\title{
Efficacy and safety of galcanezumab for preventive treatment of migraine: a systematic review and meta-analysis
}

\author{
Virginia L. Stauffer ${ }^{1} \cdot$ Tina M. Oakes $^{1} \cdot$ Mallikarjuna Rettiganti $^{1} \cdot$ Kathleen A. Day $^{1} \cdot$ Angelo Camporeale $^{1}$
}

Accepted: 21 December 2020 / Published online: 15 February 2021

(c) Springer-Verlag GmbH, DE part of Springer Nature 2021

\section{Dear Sirs,}

It was with great interest that we read the manuscript recently published online 31 January 2020: Zhao X, Xu X, Li Q, Efficacy and safety of galcanezumab for preventive treatment of migraine: a systematic review and meta-analysis. J Neurol. 2020; [Epub ahead of print] [1]. While the overall conclusion is accurate, there are several errors with regard to written text and figure legends that should be corrected to more accurately reflect the results supporting the conclusion.

We appreciate the authors assessed the potential errors in the manuscript and corrected them [2]. However, there is still one question that remains on Figure 5.

The legend for Fig. 5 still appears mislabeled. Figure $5=50 \%, 75 \%$ and $100 \%$ response rates appears to inaccurately reflect the data, as the $x$-axis Favours [experimental] should be on the right side of 1 . Risk ratio in this case, is 'risk' of $x \%$ response, so higher ratio $(>1)$ for galcanezumab vs. placebo, should favor experimental drug and not control as it now says in label.

We do appreciate that the interpretation of the result is correct, "Our meta-analysis suggested galcanezumab had favorable influence on the increase in $\geq 50 \%$ response, $\geq 75 \%$ response, and $100 \%$ response. As for the control group also has a high $\geq 50 \%$ response, $\geq 75 \%$ response, and $100 \%$ response, the reason may be to comfort the psychological function of the patients."

Thank you for your careful consideration of the above.

\section{Compliance with ethical standards}

Conflicts of interest All of the authors are employees of Eli Lilly and Company who is the manufacturer of galcanezumab and have no other conflicts of interest to this study or its results.

Ethical standards statement Not applicable.

\section{References}

1. Zhao X, Xu X, Li Q (2020) Efficacy and safety of galcanezumab for preventive treatment of migraine: a systematic review and meta-analysis. J Neurol. https://doi.org/10.1007/s00415-02009707-5

2. Zhao X, Xu X, Li Q (2020) Correction to: efficacy and safety of galcanezumab for preventive treatment of migraine: a systematic review and meta-analysis. J Neurol. https://doi.org/10.1007/s0041 5-020-10337-0
Virginia L. Stauffer

vstauffer@lilly.com

1 Lilly Research Laboratories, Lilly Corporate Center, Indianapolis, IN, USA 